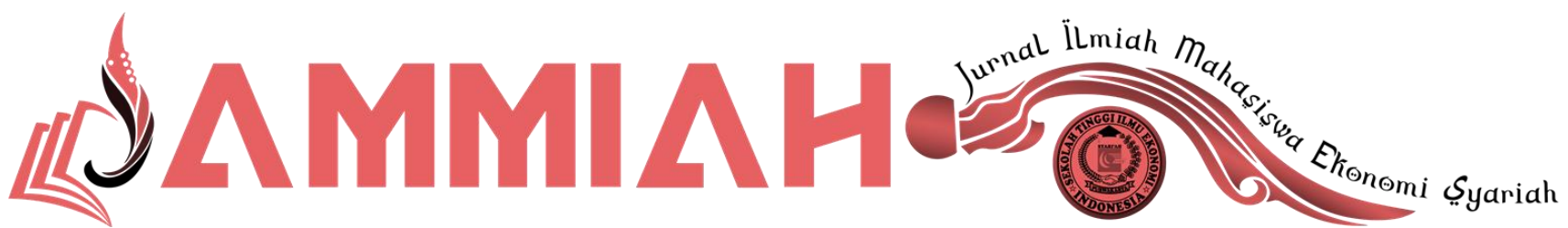

Volume 1 Nomor 1, Maret 2021

DOI: https://doi.org/10.37726/

\section{Mekanisme Absensi Karyawan Departemen Lab Inspection di PT. Metro Pearl Indonesia}

\author{
Cindy Kafita Cendani \\ PT. Metro Pearl Indonesia (HDN) \\ Cindykc28@gmail.com
}

\begin{abstract}
ABSTRAK
Adanya persaingan bisnis mendorong suatu perusahaan untuk menciptakan suatu inovasi untuk bersaing unggul dalam kondisi apapun. Salah satu cara untuk dapat mencapai perusahaan yang unggul dimulai dari diterapkannya sistem manajamen operasional dalam perusahaan tersebut. Tujuan dari penelitian ini adalah untuk mengetahui tentang Mekanisme Absensi Karyawan Departemen Lab Inspection di PT. Metro Pearl Indonesia. Mekanisme Absensi Karyawan Departemen Lab Inspection di PT. Metro Pearl Indonesia dilakukan beberapa sistem terhadap setiap laporannya, beberapa diantaranya yaitu penjadwalan jam kerja karyawan, lemburan, sistem laporan absensi harian, mingguan dan perubahan jadwal jam kerja karyawan yang tiap harinya diinput dan diupdate melalui email yang dikirimkan ke attandance dengan atas sepengetahuan dan persetujuan manajer Departemen Lab Inspection. Kata kunci- Mekanisme Absensi, Absensi Karyawan, Departemen Lab Inspection.
\end{abstract}

\section{ABSTRACT}

The existence of business competition encourages a company to create an innovation to compete for excellence in any condition. One way to achieve a superior company starts from the implementation of an operational management system within the company. The purpose of this study was to find out about the Implementation of Operational Management of Employee Attendance Report at the Inspection Lab Department at PT. Metro Pearl Indonesia. Implementation of Operational Management for Attendance Report for Lab Inspection Department employees at PT.

JAMMIAH (Jurnal Ilmiah Mahasiswa Ekonomi Syariah), Volume 1, Nomor 1, Maret 2021

http://journal.sties-purwakarta.ac.id/index.php/jammiah/

ISSN: xxxx-xxxx (Media Online) xxxx-xxxx (Media Cetak) 
Metro Pearl Indonesia carries out several systems for each report, including scheduling employee work hours, overtime, daily, weekly attendance reporting systems and changes to employee work schedules which are inputted and updated daily via email sent to attendance with the knowledge and approval of the Lab Inspection manager Department.

Keywords- Implemetation, Operational Management, Employee Attendance Report, Inspection Lab Departement.

\section{PENDAHULUAN}

Manajemen operasional adalah suatu bentuk dari pengelolaan yang menyeluruh dan optimal pada sebuah masalah tenaga kerja, barang, mesin, peralatan bahan baku, atau produk apapun yang bisa dijadikan sebuah barang atau jasa yang bisa diperjual belikan. ${ }^{1}$ Dalam pelaksanaan kegiatan produksi, diperlukannya manajerial yang berguna untuk menerapakan keputusan dalam upaya pengaturan dan pengkoordinasian pernggunaan sumber daya dari kegiatan produksi yang dkenal sebagai manajemen operasional. ${ }^{2}$

Perkembangan teknologi informasi dari tahun ketahun yang semakin cepat menjadi tantangan berat bagi pengguna teknologi informasi itu sendiri dan mendorong setiap sector organisasi baik formal maupun informal atau lembagalembaga lainnya untuk dapat memanfaatkannya sebagai penunjang kegiatan kerja sehingga dapat menghasilkan informasi yang cepat, tepat dan akurat. PT. Metro Pearl Indonesia sebagai perusahaan di bidang industri sepatu tentu saja memerlukan manajemen yang baik dalam mengelola data absensi karyawannya yang nantinya akan berdampak positif bagi perkembangan perusahaan itu sendiri. Maka dibutuhkan informasi yang efisien dalam mempertahankan keberadaannya agar tetap eksis dan dikenal oleh masyarakat luas

Adanya persaingan bisnis mendorong suatu perusahaan untuk menciptakan suatu inovasi untuk bersaing unggul dalam kondisi apapun. Salah satu cara untuk dapat mencapai perusahaan yang unggul dimulai dari diterapkannya sistem manajamen operasional dalam perusahaan tersebut. ${ }^{3}$ Hal ini dapat membantu perusahaan dalam mengidentifikasi perubahan-perubahaan yang terjadi dalam lingkungan perusahaan juga merespon secara cepat terhadap perubahan tersebut melalui perbaikan secara terus menerus agar tercapainya kinerja operasional yang baik.

${ }^{1}$ Parinduri, Luthfi, Et Al. Manajemen Operasional: Teori Dan Strategi. Medan: Yayasan Kita Menulis. 2020.

2 Azis, Anton Mulyono; Irjayanti, Maya. Manajemen. Bandung: Mardika Group. 2014.

3 Widajanti, Erni. Peran Strategi Operasi Dalam Mencapai Keunggulan Kompetitif Bagi Perusahaan. Jurnal Ekonomi Dan Kewirausahaan, 2014, 14.1.

JAMMIAH (Jurnal Ilmiah Mahasiswa Ekonomi Syariah), Volume 1, Nomor 1, Maret 2021 
Perkembangan teknologi informasi dari tahun ketahun yang semakin cepat menjadi tantangan berat bagi pengguna teknologi informasi itu sendiri dan mendorong setiap sector organisasi baik formal maupun informal atau lembagalembaga lainnya untuk dapat memanfaatkannya sebagai penunjang kegiatan kerja sehingga dapat menghasilkan informasi yang cepat, tepat dan akurat. PT. Metro Pearl Indonesia sebagai perusahaan di bidang industri sepatu tentu saja memerlukan manajemen yang baik dalam mengelola data absensi karyawannya yang nantinya akan berdampak positif bagi perkembangan perusahaan itu sendiri. Maka dibutuhkan informasi yang efisien dalam mempertahankan keberadaannya agar tetap eksis dan dikenal oleh masyarakat luas

Perusahaan atau industri dituntut untuk melakukan suatu perubahan pada lingkungan kerja perusahaan yang sangat cepat dan kompetitif dalam suatu kondisi apapun ${ }^{4}$. Pada era globalisasi ini, perusahaan dituntut untuk tetap selalu dapat menjual produk dengan cara apapun. Tuntutan tersebut mendorong peusahaan untuk menggunakan konsep-konsep yang dapat membuat perusahaan untuk meningkatkan kinerja perusahaan. Namun hal tersebut juga dapat menimbulkan suatu permasalahan, ketika jumlah produksi meningkat, penyerapan tenaga bekerja bertambah permsalahan konsistensi dalam pengelolaan kualitas dipertaruhkan akibat dari jumlah produksi yang meningkat tak terkendali.

Penelitian tentang Mekanisme Absensi Karyawan Departemen Lab Inspection di PT. Metro Pearl Indonesia Terhadap Suatu Perusahaan atau Lembaga sudah banyak dilakukan oleh peneliti-peneliti sebelumnya seperti yang dilakukan oleh Adrian, Thamrin dan Jimmi Copriady ${ }^{5}$, Penelitian ini bertujuan untuk mengetahui tentang implementasi manajemen operasional limbah medis padat di Health and Medical Service Rumah Sakit PT Chevron Pacific Indonesia Distrik Duri. peneliti mengumpulkan data dari studi literatur, peraturan pemerintah, situs web dan wawancara mendalam dengan staf di Layanan Kesehatan dan Medis Chevron Pacific Indonesia District Duri, Mitra Bisnis Layanan Kesehatan dan Medis Chevron Pacific Indonesia District Duri. Hasil dari penelitian ini adalah pelaksanaan pengelolaan limbah medis di Chevron Pelayanan Kesehatan dan Medis Pacific Indonesia District Duri telah dilakukan kerjasama dengan Hasakona Bina cipta sebagai Mitra Bisnis dengan langkah-langkah penahanan sampah, pengumpulan sampah, membuang sampah, mengelola sampah dengan mesin incinerator. kualitasnya kuat dalam

${ }^{4}$ Ibrahim, Akhmadrandy. Analisis Implementasi Manajemen Kualitas Dari Kinerja Operasional Pada Industri Ekstraktif Di Sulawesi Utara. Jurnal Emba: Jurnal Riset Ekonomi, Manajemen, Bisnis Dan Akuntansi, 2016, 4.2 .

${ }^{5}$ Adrian, Adrian; Thamrin, Thamrin; Copriady, Jimmi. Implementasi Manajemen Operasional Limbah Medis Padat Di Rumah Sakit Pt. Chevron Pacifik Indonesia. Jurnal Ilmu Lingkungan, 2016, 10.1: 87-97.

JAMMIAH (Jurnal Ilmiah Mahasiswa Ekonomi Syariah), Volume 1, Nomor 1, Maret 2021 
sambungan, parameter kualitas air diukur pada 64,8\% total bakteri yang terpengaruh dan 35,2\% dipengaruhi oleh faktor lain. Selanjutnya penelitian dilakukan oleh Nunung Hidayatun ${ }^{6}$, Hasil penelitian tersebut disampaikan bahwa setelah dilakukan analisis ditemukannya masalah yang terjadi pada sistem penggajian karyawan dan ditemukannya solusi terbaik untuk mengatasi masalah pada sistem penggajian dengan memanfaatkan CBIS diterapkannya aplikasi program penggajian karyawan.

Penelitian-penelitian tersebut hanya mengkaji implementasi manajemen operasional pada limbah medis padat dan sistem penggajian karyawan saja tidak dengan Manajemen operasional pada laporan absensi karyawan.

Penelitian ini mengkaji lebih dalam tentang bagaimana implementasi manajemen operasional pada Laporan absensi karyawan di departemen suatu perusahaan sepatu atau industri sepatu. Penulis terfokus pada satu industri sepatu atau perusahaan sepatu yang bertempat di Purwakarta yaitu PT. Metro Pearl Indonesia. Yang dimana penulis mengambil data dan informasi hanya pada salah satu departemen yang ada di PT. Metro Pearl Indonesia.

Fokus penelitian ini adalah untuk mengetahui tentang Implementasi Manajemen Operasional pada Laporan Absensi Karyawan Departemen Lab Inspection di PT. Metro Pearl Indonesia.

\section{TINJAUAN PUSTAKA}

Manajemen operasional ialah suatu bentuk dari pengelolaan yang menyeluruh dan optimal pada sebuah masalah tenaga kerja, barang, mesin, peralatan, bahan baku, atau produk apapun yang bisa dijadikan sebuah barang atau jasa yang bisa diperjual belikan. Kegiatan yang merupakan tanggung jawab dari manajer operasional terhadap penghasilan produk atau jasa, mengambil sebuah keputusan yang berhubungan dengan fungsi operasi dan sistem transformasi. ${ }^{7}$ dan menimbangkan pengambilan keputusan dari fungsi operasi. Dalam pelaksanaan kegiatan produksi perusahaan, diperlukan manajerial yang berguna untuk menerapkan keputusan keputusan dalam upaya pengaturan dan pengkoordinasian penggunaan sumber daya dari kegiatan produksi yang dikenal sebagai manajemen operasional. ${ }^{8}$

Penelitian tentang Implementasi Manajemen Operasional terhadap Suatu Perusahaan atau Lembaga sudah banyak dilakukan oleh peneliti-peneliti sebelumnya

${ }^{6}$ Hidayatun, Nunung. Problem Solving Sistem Penggajian Karyawan Dalam Manajemen Operasional Komputer Menggunakan Pendekatan Sistem. Ijcit (Indonesian Journal On Computer And Information Technology), 2016, 1.2.

7 Panji Anoraga. Manajemen Bisnis. Jakarta: Sinema Cipta. 2009.

${ }^{8}$ Efendi, Suryono; Pratiknyo, Djoko; Sugiono, Edi. Manajemen Operasional. Jakarta: Lembaga Penerbitan Universitas Unas. 2019.

JAMMIAH (Jurnal Ilmiah Mahasiswa Ekonomi Syariah), Volume 1, Nomor 1, Maret 2021 
seperti yang dilakukan oleh Sri Rohaetin dan Intan Nurrahmi ${ }^{9}$, Hasil penelitian ini menunjukkan bahwa manajemen operasional desain produk yang tepat untuk meningkatkan hasil penjualan produk UKM Rotan Grup Pahari Palangka Raya adalah dengan menerapkan delapan aspek desain produk (bentuk, fitur, kinerja, kesesuaian, keawetan, keandalan, gaya, dan kemudahan perbaikan) dengan mengutamakan produk dan harga yang dipasarkan. Dan dalam pengelolaan operasional rantai pasok yang tepat untuk meningkatkan hasil produksi UKM Kelompok Rotan Pahari Palangkaraya dengan menerapkan strategi

Selanjutnya penelitian dilakukan oleh Cahya Vikasari ${ }^{10}$. Hasil dari penelitian ini adalah sistem ini dapat mempermudah pengelolaan manajemen operasioal travel kendaraan sehingga dapat mengefektifkan proses yang ada, meningkatkan pelayanan kepada konsumen, mempermudah pada saat pencarian data yang berkaitan dengan data travel kendaraan.

Peneliti selanjutnya yaitu Kresna Ramanda ${ }^{11}$, Hasil dari penelitian tersebut yaitu dengan adanya sistem komputerisasi yang melayani pelanggan dalam memesan makanan di chicken bonchon indonesia selain membantu meningkatkan produktivitas juga membantu melakukan efektifitas pelayanan terhadap pelanggan. Sehingga antrian yang panjang dalam memesan makanan bisa terhindarkan. Oleh karena itu untuk mempercepat proses pemesanan makanan dibutuhkan suatu aplikasi yang baru untuk dapat mengatasi kelemahan-kelemahan sistem informasi yang ada, yaitu program aplikasi Sistem pemesanan menu makanan yang terkomputerisasi agar pelayanan dapat diberikan lebih cepat, tepat dan aktual sehingga mencapai hasil yang diharapkan.

Perbedaan dengan peneliti sebelumnya yaitu penulis sekarang meneliti implementasi manajemen operasional pada laporan absensi karyawan suatu perusahaan sepatu atau industri sepatu yang dimana tidak dikaji atau diteliti oleh peneliti sebelumnya. Dan juga peneliti sebelumnya hanya terfokus pada bidang pelayanan jasa bukan pada bidang pembuatan barang.

${ }^{9}$ Rohaetin, Sri; Norrahmi, Intan. Analisis Penerapan Manajemen Operasional (Desain Produk Dan Rantai Pasokan) Pada Ukm Rotan Kelompok Pahari Palangka Raya. Equilibrium: Jurnal Ilmiah Ekonomi Dan Pembelajarannya, 2020, 8.2: 155-165.

10 Vikasari, Cahya. Sistem Manajemen Operasional Jasa Travel Kendaraan Dalam Meningkatkan Pelayanan Perusahaan. Jurnal Informatika: Jurnal Pengembangan It, 2018, 3.2: 271-276.

${ }^{11}$ Ramanda, Kresna. Penerapan Sistem Manajemen Operasional Pelayanan Pemesanan Menu Makanan Dengan Waiting Line Method. Jurnal Pilar Nusa Mandiri, 2016, 12.2: 182-189.

JAMMIAH (Jurnal Ilmiah Mahasiswa Ekonomi Syariah), Volume 1, Nomor 1, Maret 2021 


\section{HASIL DAN PEMBAHASAN}

Dalam suatu perusahaan akan selalu ada permasalahan yang dapat menimbulkan dampak negatif terhadap perusahaan. Oleh karena itu, dalam menjalankan kegiatannya perusahaan perlu menerapkan upaya pencegahan untuk mengurangi dampak dari permsalahan yang mungkin terjadi. Perusahaan yang penulis teliti memiliki beberapa departemen bagian lainnya, namun dalam penelitian ini penulis hanya meneliti Mekanisme Absensi Karyawan Departemen Lab Inspection di PT. Metro Pearl Indonesia. Berdasarkan hasil penelitian pada departemen perusahaan tersebut, penulis mendapatkan data atau informasi selama penelitian berlangsung yaitu tentang sistem absensi di perusahaan tersebut, perusahaan memberikan tugas tersebut kepada setiap personalia di departemennya masing-masing untuk melakukan pengolahan data laporan absensi harian, mingguan dan bulanan karyawan dengan membuat laporan jadwal jam kerja, daftar kehadiran karyawan dan data lemburan tiap karyawan melalui email yang dikirim ke bagian attendance dan dengan pemberitahuan kepada tiap manajer masing-masing departemen ${ }^{12}$.

\section{A. Pengiriman Jadwal Kerja Karyawan}

Sebelum pengiriman jadwal kerja karyawan, personalia harus memastikan kepada setiap atasan nama-nama karyawan yang bekerja dan dibagi shift sesuai dengan bidang kerjanya masing-masing. Setelah memastikan jadwal kerja karyawan, personalia mebuat data jadwal kerja karyawan yang sudah pasti dengan menggunakan format excel. Dalam data pengaturan jadwal kerja karyawan personalia membutuhkan data karyawan tersebut, mulai dari nama lengkap, NIK, dan job code karyawan tersebut untuk dimasukan kedalam data tersebut. Setelah itu, personalia mengirimkan jadwal kerja dan lemburan karyawan selama satu bulan melalui email untuk menginformasikan atau menkonfirmasi kepada attendance tentang pembagian shift dan lemburan karyawan pada departemen tersebut sebagai data atau catatan untuk attendance. Data jadwal tersebut bukan hanya diketahui dan disetujui oleh atasan departemen lab inspection saja tetapi juga dengan atas disetujui oleh manajer HRM di PT. Metro Pearl Indonesia.

\section{Gambar 3.1}

Jadwal Kerja Karyawan

12 Simargolang, Muhammad Yasin; Warsito, Wiyoga Agung. Analisis Sistem Pengolahan Absensi Karyawan Pada Pt. Bakrie Sumatera Plantations Tbk Bunut. Jurti (Jurnal Teknologi Informasi), 2018, 1.2: 114124.

JAMMIAH (Jurnal Ilmiah Mahasiswa Ekonomi Syariah), Volume 1, Nomor 1, Maret 2021 


\begin{tabular}{|c|c|c|c|c|c|}
\hline \multicolumn{5}{|c|}{ 7-11 DESEMBER 2020} & \multirow{2}{*}{ TTD } \\
\hline No & NAMA & JOB CODE & DEPT & JADWAL SHIFT & \\
\hline 1 & DIAN ROSDIANA & 100158 & \multirow{2}{*}{ RHEOMETER } & $07.00-16.00$ & \\
\hline 2 & CINDY KAFITA C & 100169 & & $21.00-06.00$ & \\
\hline \multirow{2}{*}{\multicolumn{5}{|c|}{ 14-18 DESEMBER 2020}} & \multirow{3}{*}{ TTD } \\
\hline & & & & & \\
\hline No & NAMA & JOB CODE & DEPT & JADWAL SHIFT & \\
\hline 1 & CINDY KAFITA CENDANI & 100169 & \multirow{2}{*}{ RHEOMETER } & $07.00-16.00$ & \\
\hline 2 & DIAN ROSDIANA & 100158 & & $21.00-06.00$ & \\
\hline & & \multirow{2}{*}{\multicolumn{2}{|c|}{$21-23$ DESEMBER 2020}} & - & \\
\hline & & & & & \multirow{2}{*}{ TTD } \\
\hline No & NAMA & JOB CODE & DEPT & JADWAL SHIFT & \\
\hline 1 & DIAN ROSDIANA & 100158 & \multirow{2}{*}{ RHEOMETER } & $07.00-16.00$ & \\
\hline 2 & CINDY KAFITA C & 100169 & & $21.00-06.00$ & \\
\hline \multicolumn{5}{|c|}{ 28-31 DESEMBER 2020} & \multirow[b]{2}{*}{ TTD } \\
\hline No & NAMA & JOB CODE & DEPT & JADWAL SHIFT & \\
\hline 1 & CINDY KAFITA CENDANI & 100169 & \multirow{2}{*}{ RHEOMETER } & $07.00-16.00$ & \\
\hline 2 & DIAN ROSDIANA & 100158 & & $21.00-06.00$ & \\
\hline & Dedeh Purwanengsih & \multirow{2}{*}{\multicolumn{2}{|c|}{ Detty Puspita }} & \multirow{2}{*}{\multicolumn{2}{|c|}{$\begin{array}{c}\text { Evad Fadli } \\
\text { (Manager HRM) }\end{array}$}} \\
\hline & (Kabag Lab) & & & & \\
\hline
\end{tabular}

Gambar 3.2

Form Lemburan

FT. METRO PEARL INDONESIA

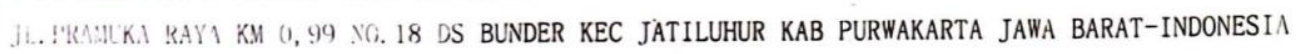

* $\quad$ No. Doc:02/001/HR/MPI/X/2011

Revise: 3

Effective date:11 Oktober 2011

4. 11. Whatham hailwa dengan menandatangani formulir ini, kami setuju untuk melakukan lembur secara

. Awiscia dengali jadwal yang telah ditentukan perusahaan dibawah ini.

\begin{tabular}{|c|c|c|c|c|c|c|}
\hline No & NIK & JobCode & Name & Jam & $\begin{array}{c}\text { Break } \\
\text { Time }\end{array}$ \\
\hline$!$ & $16110 \times 370$ & I00169 & Cindy Kafita Cendani & $07: 00-15: 00$ & 1 & ( A \\
\hline
\end{tabular}

'1' 28, August, 2020

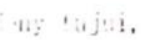

(M:arager)

$M x^{9} / 28$

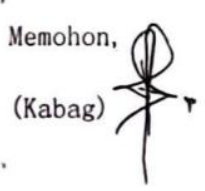

\section{B. Laporan Harian dan Mingguan Absensi Karyawan}

PT. Metro Pearl Indonesia, membagi laporan absensi karyawan menjadi dua bagian yaitu laporan absensi harian dan mingguan. Tujuan dari kedua laporan tersebut yaitu agar memudahkan personalia dan atasan untuk mengorganisir dan mengontrol data kehadiran karyawan departemen lab inspection PT. Metro Pearl

JAMMIAH (Jurnal Ilmiah Mahasiswa Ekonomi Syariah), Volume 1, Nomor 1, Maret 2021

http://journal.sties-purwakarta.ac.id/index.php/jammiah/

ISSN: xxxx-xxxx (Media Online) xxxx-xxxx (Media Cetak) 
Indonesia ${ }^{13}$. Setelah dibuatkan laporan-laporan tersebut, personalia mengirimkan laporan tersebut melalui email kepada attendance, kabag dan manajer departemen lab inspection agar para atasan mengetahui siapa saja karyawan yang tidak masuk pada hari itu.

Gambar 3.3

Laporan Harian Absensi Karyawan ABSENSI KARYAWAN DEPT. LAB/INSPECTION/CE

\begin{tabular}{|c|c|c|c|c|c|c|c|c|c|c|}
\hline & \multirow{3}{*}{ BAGIAN 单位 } & \multirow{3}{*}{$\begin{array}{c}\text { Total } \\
\text { Karyawan 应 } \\
\text { 到人员 }\end{array}$} & \multirow{3}{*}{$\begin{array}{c}\text { Total } \\
\text { Karyawan } \\
\text { Yang Hadir 实 } \\
\text { 到人员 }\end{array}$} & \multirow{3}{*}{$\begin{array}{c}\text { Total } \\
\text { Karyawan } \\
\text { Yang Tidak } \\
\text { Hadir 缺勤 }\end{array}$} & & & & & & Selasa, 25 Agustus 2020 \\
\hline \multirow{2}{*}{ No } & & & & & \multirow{2}{*}{$\%$} & \multicolumn{4}{|c|}{ Absen 考勤状况 } & \multirow{2}{*}{ Keterangan 备注 } \\
\hline & & & & & & $\begin{array}{l}\text { Alpa } \\
\text { 旷工 }\end{array}$ & $\begin{array}{c}\text { Ijin } \\
\text { 请假 }\end{array}$ & $\begin{array}{c}\text { Skd } \\
\text { 病假 }\end{array}$ & $\begin{array}{l}\text { Cuti } \\
\text { 休假 }\end{array}$ & \\
\hline 1 & LAB & 15 & 13 & 2 & & & & & 2 & $\begin{array}{l}\text { 1. Nindia Indriani (CML) } \\
\text { 2. Ruswana }\end{array}$ \\
\hline 2 & Inspection & & & & & & & & & \\
\hline 3 & CE & & & & & & & & & \\
\hline 4 & CLERK 班长 & 1 & 0 & 1 & & & & & 1 & 1. Sari Oktariany \\
\hline 5 & SPV 部长 & 2 & 2 & & & & & & & \\
\hline 6 & Kabag & 1 & 1 & & & & & & & \\
\hline 7 & Manager 经历 & 1 & 1 & & & & & & & \\
\hline & TOTAL 合计 & & & & & & & & & \\
\hline
\end{tabular}

Gambar 3.4

Email Laporan Mingguan Absensi Karyawan

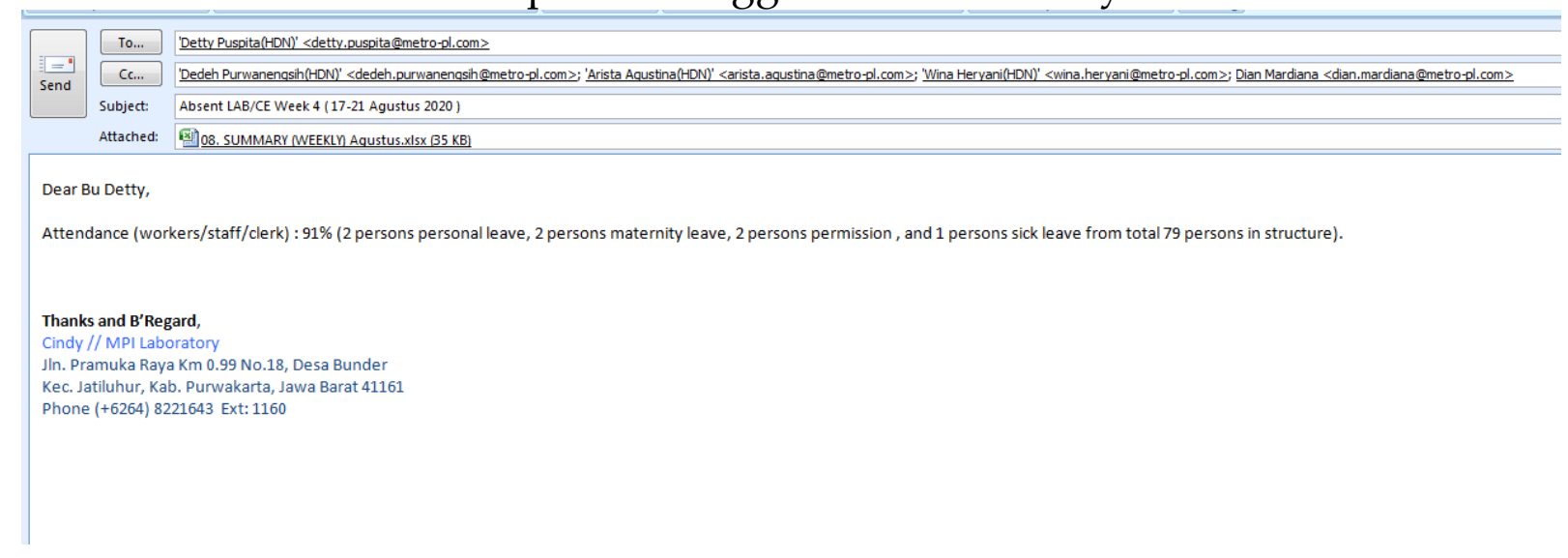

Selain data-data laporan tersebut, departemen lab inspcetion PT. Metro Pearl Indonesia juga membuat rekap data absensi karyawan untuk internal departemen tersebut yang lebih terperinci dari laporan-laporan absensi lainnya.

Gambar 3.5

Rekap Data Absensi Mingguan

${ }^{13}$ Al-Harits, Achmad Misbahuddin. Lkp: Rancang Bangun Aplikasi Absensi Karyawan Berbasis Web Pada Pt Indoberka Investama. 2017. Phd Thesis. Institut Bisnis Dan Informatika Stikom Surabaya.

JAMMIAH (Jurnal Ilmiah Mahasiswa Ekonomi Syariah), Volume 1, Nomor 1, Maret 2021 


Absent Karyawan Departement Lab/Inspecion/CE
\begin{tabular}{|c|l|c|c|c|c|c|c|c|c|}
\hline \multirow{2}{*}{ No } & \multicolumn{1}{|c|}{ Nama } & NIK & Jobcode & Dept & \multicolumn{3}{|c|}{$\mathbf{1 7 - 2 1}$ Agustus 2020 } \\
\cline { 6 - 10 } & & & & & SENIN & SELASA & RABU & KAMIS & JUMAT \\
\hline 1 & Dedeh Purwanengsih & 110500255 & N04002 & Lab & & $\mathbf{V}$ & $\mathbf{V}$ & & $\mathbf{V}$ \\
\hline 2 & Dian Mardiana & 140805680 & N06093 & Lab & & $\mathbf{V}$ & $\mathbf{V}$ & & $\mathbf{V}$ \\
\hline 3 & Dhini Cahya Permata & 121203852 & N07046 & Lab & & $\mathbf{V}$ & $\mathbf{V}$ & & $\mathbf{V}$ \\
\hline 4 & Sari Oktariany & 111201699 & N10040 & Lab & & $\mathbf{V}$ & $\mathbf{V}$ & & $\mathbf{V}$ \\
\hline 5 & Ira Nurohmi & 130303976 & 100175 & Lab & & $\mathbf{V}$ & $\mathbf{V}$ & & $\mathbf{V}$ \\
\hline 6 & Resa Aldiana & 150606996 & 100058 & Lab & & $\mathbf{V}$ & $\mathbf{V}$ & & $\mathbf{V}$ \\
\hline 7 & Gianti Pramesty C & 150907202 & 100159 & Lab & & $\mathbf{S A K I T}$ & $\mathbf{S A K I T}$ & & $\mathbf{S A K I T}$ \\
\hline 8 & Dian Rosdiana & 150907110 & 100158 & Rheometer & & $\mathbf{C U T I}$ & $\mathbf{V}$ & & $\mathbf{V}$ \\
\hline 9 & Cindy Kafita Cendani & 161108370 & 100169 & Rheometer & & $\mathbf{V}$ & $\mathbf{V}$ & & $\mathbf{V}$ \\
\hline 10 & Riki Andika & 120903333 & 100033 & Lab & & $\mathbf{V}$ & $\mathbf{V}$ & & $\mathbf{V}$ \\
\hline 11 & Ryan Ryanto & 160307776 & 100174 & Lab & & $\mathbf{V}$ & $\mathbf{V}$ & & $\mathbf{V}$ \\
\hline
\end{tabular}

\begin{tabular}{|l|l|l|l|l|l|l|l|l|}
\hline Keterangan: & & & & & & & & \\
\hline \hline IZIN & & & & & & 2 & & 1 \\
\hline ALFA & & & & & & & & \\
\hline \hline CUTI & & & & & 4 & 2 & & 2 \\
\hline \hline SAKIT & & & & & 1 & 1 & & 1 \\
\hline TOTAL ABSENT & & & \multicolumn{7}{|c|}{ 14 KARYAWAN } \\
\hline
\end{tabular}

\section{Prosedur Absensi Masuk Kerja}

Suatu sistem merupakan suatu kegiatan prosedur dari proses yang sedang berjalan untuk menghasilkan efektifitas kerja, agar dapat memberikan hasil yang sesuai tujuan yang diharapkan dengan memanfaatkan teknologi dan fasilitas yang tersedia. Maka dari itu perusahaan mengunakan sistem sidik jari untuk seluruh karyawan sebagai tanda bukti kehadiran karyawan tersebut yang dimana data kehadiran karyawan tersebut tidak dapat dimanipulasi ${ }^{14}$. Prosedur absensi yang dilakukan adalah sebagai berikut :

1. Setiap karyawan melakukan absensi setiap hari kerja dan melakukan finger print atau sidik jari pada alat absensi yang telah disediakan. Sistem tersebut akan langsung merekap absensi karyawan siapa-siapa saja yang terlambat dan tidak masuk secara otomatis.

2. Departemen IT di perusahaan tersebut menerina laporan absensi karyawan setiap harinya sebagai data untuk dilaporkan kepada attendance yang nantinya dilaporkan kepada atasan departemen lab inspection untuk diolah sebagai penilaian kinerja karyawan dalam perusahaan.

14 Thenady, Hans Sebastian; Setiawan, Alexander; Noertjahyana, Agustinus. Pembuatan Program Absensi Sidik Jari Untuk Bagian Pergudangan Pt. Puji Surya Indah. Jurnal Infra, 2019, 7.2: 220-226.

JAMMIAH (Jurnal Ilmiah Mahasiswa Ekonomi Syariah), Volume 1, Nomor 1, Maret 2021 
Namun ketika karyawan tidak atau lupa melakukan finger print, attendance akan mengkonfirmasi kepada personalia departemen lab inspection bahwa karyawan tersebut tidak melakukan finger print. Maka personalia akan membuat laporan abnormal sebagai konfirmasi bahwa karyawan tersebut telah masuk kerja sesuai dengan yang dijadwalkan dan ditandatangani oleh kabag dan manajer departemen lab inspection dan disertai tandatangan saksi yang menyaksikan bahwa karyawan tersebut benar-benar masuk kerja sesuai jadwal yang telah ditetapkan.

\section{Perubahan Jadwal Jam Kerja}

Dalam suatu perusahaan akan selalu ada permasalahan yang dimana perusahaan harus mengambil keputusan untuk merubah suatu aktivitas yang telah direncanakan sebelumnya ${ }^{15}$. Dalam hal jadwal jam kerja pun tak jarang perusahaan harus merubahnya sewaktu-waktu ketika tejadi suatu permasalahan yang mengharuskannya untuk merubah. Hal yang dilakukan ketika ada perubahan jadwal jam kerja karyawan pada hari tersebut, maka personalia harus mengisi form perubahan jadwal secara manual dan juga melaporkan perubahan tersebut melalui email kepada attendance dengan sepengetahuan manajer.

Dari data-data tersebut dengan adanya sistem laporan absensi harian, mingguan dan prosedur masuk kerja menggunakan finger print atau sidik jari, telah membuktikan bahwa Departemen Lab Inspection PT Metro Pearl Indonesia telah mengimplementasikan manajemen operasional laporan absensi karyawan. Sehingga departemen lab inspection PT. Metro Pearl Indonesia dapat mengontrol dan mengorganisir karyawan dengan baik dan efisien.

\section{KESIMPULAN}

Mekanisme Absensi Karyawan Departemen Lab Inspection di PT. Metro Pearl Indonesia dilakukan beberapa sistem terhadap setiap laporannya, beberapa diantaranya yaitu penjadwalan jam kerja karyawan, lemburan, sistem laporan absensi harian, mingguan dan perubahan jadwal jam kerja karyawan yang tiap harinya diinput dan diupdate melalui email yang dikirimkan ke attandance dengan atas sepengetahuan dan persetujuan manajer Departemen Lab Inspection. Hasil Penelitian ini memperkuat Penelitian terdahulu yang dilakukan oleh Kresna Ramanda.

${ }^{15}$ Setiawan, Septian Budi. Pengaruh Perubahan Waktu Gilir Kerja Sebagai Dampak Covid-19 Terhadap Kinerja Karyawan (Studi Kasus: Pt. Nusa Halmahera Mineral, Maluku Utara). Jurnal Manajemen Pendidikan Dan Ilmu Sosial, 2020, 1.1: 234-243.

JAMMIAH (Jurnal Ilmiah Mahasiswa Ekonomi Syariah), Volume 1, Nomor 1, Maret 2021 
Artikel Jurnal

\section{DAFTAR PUSTAKA}

Adrian, Adrian; Thamrin, Thamrin; Copriady, Jimmi. (2016). Implementasi Manajemen Operasional Limbah Medis Padat Di Rumah Sakit Pt. Chevron Pacifik Indonesia. Jurnal Ilmu Lingkungan, 10.1.

Al-Harits, Achmad Misbahuddin. (2017). Lkp: Rancang Bangun Aplikasi Absensi Karyawan Berbasis Web Pada Pt Indoberka Investama. Phd Thesis. Institut Bisnis Dan Informatika Stikom Surabaya.

Hidayatun, Nunung. (2016). Problem Solving Sistem Penggajian Karyawan Dalam Manajemen Operasional Komputer Menggunakan Pendekatan Sistem. Ijcit (Indonesian Journal On Computer And Information Technology). 1.2.

Ibrahim, Akhmadrandy. (2016). Analisis Implementasi Manajemen Kualitas Dari Kinerja Operasional Pada Industri Ekstraktif Di Sulawesi Utara. Jurnal Emba: Jurnal Riset Ekonomi, Manajemen, Bisnis Dan Akuntansi. 4.2.

Ramanda, Kresna. (2016). Penerapan Sistem Manajemen Operasional Pelayanan Pemesanan Menu Makanan Dengan Waiting Line Method. Jurnal Pilar Nusa Mandiri. 12.2.

Rohaetin, Sri; Norrahmi, Intan. (2020). Analisis Penerapan Manajemen Operasional (Desain Produk Dan Rantai Pasokan) Pada Ukm Rotan Kelompok Pahari Palangka Raya. Equilibrium: Jurnal Ilmiah Ekonomi Dan Pembelajarannya. 8.2.

Setiawan, Septian Budi. (2020). Pengaruh Perubahan Waktu Gilir Kerja Sebagai Dampak Covid-19 Terhadap Kinerja Karyawan (Studi Kasus: Pt. Nusa Halmahera Mineral, Maluku Utara). Jurnal Manajemen Pendidikan Dan Ilmu Sosial. 1.1.

Simargolang, Muhammad Yasin; Warsito, Wiyoga Agung. (2018). Analisis Sistem

Pengolahan Absensi Karyawan Pada Pt. Bakrie Sumatera Plantations Tbk Bunut. Jurti (Jurnal Teknologi Informasi). 1.2.

Thenady, Hans Sebastian; Setiawan, Alexander; Noertjahyana, Agustinus. (2019). Pembuatan Program Absensi Sidik Jari Untuk Bagian Pergudangan Pt. Puji Surya Indah. Jurnal Infra. 7.2.

Vikasari, Cahya. (2018). Sistem Manajemen Operasional Jasa Travel Kendaraan Dalam Meningkatkan Pelayanan Perusahaan. Jurnal Informatika: Jurnal Pengembangan It. 3.2.

Widajanti, Erni. (2014). Peran Strategi Operasi Dalam Mencapai Keunggulan Kompetitif Bagi Perusahaan. Jurnal Ekonomi Dan Kewirausahaan. 14.1.

Buku

JAMMIAH (Jurnal Ilmiah Mahasiswa Ekonomi Syariah), Volume 1, Nomor 1, Maret 2021 http://journal.sties-purwakarta.ac.id/index.php/jammiah/ 
Azis, Anton Mulyono; Irjayanti, Maya. (2014). Manajemen. Bandung: Mardika Group. Efendi, Suryono; Pratiknyo, Djoko; Sugiono, Edi. (2019). Manajemen Operasional. Jakarta: Lembaga Penerbitan Universitas UNAS.

Panji Anoraga (2009). Manajemen Bisnis, Jakarta: Sinema Cipta.

Parinduri, Luthfi, Et Al. (2020). Manajemen Operasional: Teori Dan Strategi. Medan: Yayasan Kita Menulis.

Suryanto, Mikael Hang. (2016). Sistem Operasional Manajemen Distribusi. Jakarta: Gramedia Widiasarana. 